\title{
Reabilitação psicossocial: entre a segurança e ética da existência
}

Psychosocial rehabilitation: between security and the ethics of existence

Rehabilitación psicosocial: entre la seguridad y la ética de la existencia

Jessica Batista Araújo

Tiago Cassoli

Universidade Federal de Goiás, UFG, Goiânia, GO, Brasil

\begin{abstract}
Resumo
O seguinte artigo tem como objetivo mapear as práticas e pensar nas possíveis resistências à captura da vida pelas políticas públicas de reabilitação psicossocial com usuários de álcool e outras drogas. Utilizando do metodológico da cartografia, acompanhei o cotidiano de um Centro de Atenção Psicossocial álcool e outras drogas do interior de Goiás, registrando a experiência em um diário de campo. Deparei-me com a toda a diversidade teórica e prática da reabilitação psicossocial, atravessadas pelos diagramas do proibicionismo e antiproibicionismo. Analisadas dentro de uma racionalidade neoliberal, como traz Foucault, as práticas de reabilitação psicossocial de usuários de álcool e outras drogas acompanham de perto os movimentos da população modulando condutas e o consumo de drogas. Porém, agenciada à política de redução de danos, também permite linhas de subjetivação, que possibilita a construção de modos singulares de existência, perpassadas pelo cuidado de si, e não inserido simplesmente em um código moral.
\end{abstract}

Palavras-chave: Reabilitação Psicossocial; Drogas; Redução de Danos.

\begin{abstract}
The following article aims to map the psychosocial rehabilitation practices with users of alcohol and other drugs and think of the possibles resistances to the capture of life by publics policies. Using the methodology of cartography, I followed the daily routine of a CAPS ad from the interior of Goiás, recording the experience in a field diary. I came across all the theoretical and practical diversity of psychosocial rehabilitation, traversed by the prohibitionist and anti-prohibitionist diagrams. Analyzed within a neoliberal rationality, as Foucault brings, the practices of psychosocial rehabilitation of users of alcohol and other drugs closely follow the movements of the population modulating behaviors and drug consumption. However, it is also linked to the policy of harm reduction. It also allows subjectivation, which enables the construction of singular modes of existence, pervaded by self-care, and not simply inserted in a moral code.
\end{abstract}

Keywords: Psychosocial Rehabilitation; Drugs; Harm Reduction.

\section{Resumen}


El siguiente artículo tiene como objetivo mapear las prácticas y pensar en posibles resistencias a la captura de la vida por parte de las políticas públicas de rehabilitación psicosocial con usuarios de alcohol y otras drogas. Utilizando el metodológico de la cartografía, acompañé el cotidiano de un CAPS ad del interior de Goiás, registrando la experiencia en un diario de campo. Me encontré con toda la diversidad teórica y práctica de la rehabilitación psicosocial, atravesadas por los diagramas del prohibicionismo y antiprohibicionismo. Analizadas dentro de una racionalidad neoliberal, como trae Foucault, las prácticas de rehabilitación psicosocial de usuarios de alcohol y otras drogas acompañan de cerca los movimientos de la población modulando conductas y el consumo de drogas. Sin embargo, agenciada a la política de reducción de daños, también permite líneas de subjetivación, que posibilitan la construcción de modos singulares de existencia, atravesadas por el cuidado de sí, y no insertado simplemente en un código moral.

Palabras clave: Rehabilitación Psicosocial; Drogas; Reducción de Daños.

\section{Introdução}

Fruto de uma jornada de mestrado acadêmico, este artigo se propõe a mapear as práticas de reabilitação psicossocial com usuários de álcool e outras drogas e pensar nas possíveis resistências à captura da vida pelas políticas públicas sobre drogas a partir das seguintes problemáticas: quais são os interesses políticos e econômicos destas práticas? Quais alianças ocorreram para cumprir seus objetivos? Como ocorre a relação entre os saberes (médicos, psiquiátricos e jurídicos) e as práticas de reabilitação psicossocial de usuários de álcool e outras drogas? Para tanto, faremos alguns recortes históricos desse objeto buscando sua proveniência como dispositivo, evidenciando principalmente suas linhas de saber, poder e de produção de subjetivação, para finalmente nos posicionarmos a favor da vida e suas práticas de resistências.

Apesar de nascer em 1940 nos Estados Unidos, a reabilitação psicossocial só se torna um campo de estudo e prática relevante a partir da década de 1970, período em que diversos processos de reformas psiquiátricas despontam no cenário mundial (Guerra, 2004; Anthony \&Farkas, 2009). A despeito da pluralidade de experiências reformistas, todas elas giram em torno do questionamento do poder do médico psiquiatra, seja para retomar sua eficácia, seja pelo desmonte da instituição onde esse poder é exercido (Foucault, 2006).

Como alternativa aos hospitais psiquiátricos, propõe-se então um cuidado em meio aberto a partir de dispositivos territoriais e comunitários que objetivam: 1) a inclusão social desses indivíduos na comunidade, assim como 2) preparar a 
comunidade para recebê-los. O agenciamento entre as drogas e a reabilitação psicossocial no Brasil se deu justamente nesse contexto de Reforma Psiquiátrica no final dos anos setenta quando se inicia o movimento de questionamento sobre a eficácia dos dispositivos já existentes para tratar da questão do usuário de drogas.

Até 2003 os dispositivos de cuidado para usuários de álcool e outras drogas eram fundamentalmente do campo jurídico-médico, sendo delegado às instituições filantrópicas religiosas ou jurídicas-policiais. A publicação da Política de Atenção Integral aos Usuários de Álcool e Outras Drogas pelo Ministério da Saúde (Brasil, 2003) marcou a transição da questão para o campo da saúde pública. A partir de então, as formas de cuidado passam a ser alinhadas com os princípios da Reforma Psiquiátrica e os Centros de Atenção Psicossociais em sua modalidade álcool e outras drogas passam a ser o local de referência para essa gestão, agenciando os dispositivos das drogas com o da reabilitação psicossocial.

Outra novidade trazida pela nova política foi o estabelecimento da política de redução de danos como política oficial e postura indispensável aos serviços de saúde para tratar do assunto de álcool e outras drogas. Calcada nos direitos humanos, a redução de danos propõe a construção de estratégias que tenham como objetivo o aumento da qualidade de vida do indivíduo que não necessariamente precisa estar abstinente da droga que faz uso. Outra proposta é a ampliação do olhar sobre as drogas, passando agora a serem compreendidas de forma interdisciplinar, considerando o contexto sócio-histórico.

A emergência da nova proposta política e de prática coloca em cheque os regimes de verdade sobre as drogas já consolidados, tencionando a construção de um novo regime. No entanto, a emersão desses questionamentos só foi possível dentro de uma nova prática governamental que começa a se desenhar em meados do século XVIII, dentro de uma biopolítica.

Foucault (2002) nos mostra que a partir da segunda metade do século XVIII começa a aparecer uma nova tecnologia de poder que se difere das tecnologias de poder disciplinantes, uma tecnologia de poder que se aplica ao homem enquanto espécie, sobre a vida e busca reger a multiplicidade dos homens e não mais um homem individual. A nova tecnologia toma como objeto processos que são inerentes à própria vida como nascimento, longevidade, velhice, mortalidade, doenças, reprodução, etc.

Dessa forma, a biopolítica é um poder que busca a produção e ampliação da 
vida, que faz viver e deixa morrer. Para gerir as populações, o Estado moderno se apropria de uma tecnologia de poder há tempo muito usada pelo cristianismo tornando-a laica, a esse poder Foucault (1995) chama de poder pastoral. Um poder concomitantemente individualizante $\mathrm{e}$ totalizante, com vistas à condução de condutas e ordenação das probabilidades de ação da população. Esse poder ocorre na relação do pastor, médico, psiquiatra, psicólogos, etc., e os indivíduos, e na produção de saberes sobre as populações implementas pelas práticas médicas, psiquiátricas e psicológicas que agem sobre as condutas individuais e ao mesmo tempo em que retroalimentam as políticas públicas do Estado com conhecimento sobre onde incidir. É uma forma de governo dos homens, isto é, uma forma de conduzir condutas e engendrar subjetividades (Foucault, 1995).

Foucault (2008), ao discorrer sobre o conceito de governamentalidade, analisa o Estado Moderno Europeu no governo das populações e seus principais campos de conhecimentos como a economia, a estatística, a medicina social, a psiquiatria, o direito, a clínica, etc., e suas relações de poder na constituição do sujeito. $\mathrm{O}$ autor se desloca da tese de um poder Estatal repressor (teoria repressiva oriunda da psicanálise e do marxismo) e parte para uma perspectiva de análise do poder como algo instituinte, positivo, que produz e delimita as possibilidades de ações dos homens, um poder que age sobre as possíveis ações humanas.

A realidade brasileira é muito diferente desse contexto analisado por Foucault e seguiu caminhos distintos devido ao seu passado colonial, de modo que a governamentalização do Estado brasileiro se deu apenas no século XX (Gallo, 2017). No Brasil, as práticas de governamentalização se consolidam com a Constituição Federal de 1988, marco jurídico importante na constituição de um Estado de bem-estar social brasileiro, mas, ao mesmo tempo, foi neste mesmo período que houve o crescimento e fortalecimento do neoliberalismo no país, principalmente a partir do consenso de Washington e seus princípios. Assim, a governamentalidade se efetiva aqui por políticas públicas que apresenta em suas práticas elementos de um racismo de Estado, constituído em nosso passado colonial (Cassoli, 2012).

De forma particular, no Brasil, a captura da vida e produção de sujeitos se dá pelas políticas públicas. Conforme Chrispino (2016), as políticas públicas como intencionalidade de governo, inserem-se no campo das ciências políticas, uma vez que se inicia como ideia dos governantes, além de existirem em 
relação ao universo do direito, pois se transformam em ação de governo.

Após a promulgação da Constituição cidadã de 1988, como demonstra Gallo (2017), há uma maior produção de políticas públicas nos mais variados campos, construindo o processo de governamento populacional. Assim, é por meio delas que o Estado brasileiro exerce seu poder e gere a vida da população. No âmbito das drogas, Benevides e Prestes (2014) apontam que a Política Nacional Antidrogas (PNAD) de 2005, é codificada como um problema concernente à vida das populações, fazendo com que o uso de drogas funcione como instrumento e via de abertura para as práticas governamentais.

\section{Estado neoliberal e a produção de liberdade}

Dando um grande salto, pretende-se pensar nosso objeto a partir das diretrizes históricas e teóricas das políticas neoliberais europeias, americanas e brasileiras. Segundo Cassoli (2012), baseando-se em Foucault (2008), o neoliberalismo americano radicalizará a expansão da racionalidade econômica para analisar as condutas humanas entendidas, então, como um capital humano que pode ser a constituição biológica do indivíduo, mas também sua "maneira de ser", sua forma de se relacionar consigo mesmo, passando, esta também, a ser alvo das estratégias de políticas.

Assim, problematizamos o desenvolvimento do capital humano como finalidade das políticas de reabilitação de álcool e drogas que visam, hoje, atrair investimentos privados em suas ações por meio de um processo de inovação constante de suas práticas e discursos.

Tal racionalidade ultrapassa 0 limite da economia clássica dado até então por relações de troca de mercadorias e monetárias, e generaliza a grade econômica de mercado, ou seja, a lei da oferta e da procura como princípio universal de decifração/inteligibilidade das questões sociais e populacionais, assim como do governo das condutas individuais, indicando que "a análise em termos de economia de mercado, em outras palavras, em termos de oferta e procura, vai servir de esquema que se pode aplicar a campos não econômicos" (Foucault, 2008, p. 334). O neoliberalismo americano expandiu sua razão e domínio a campos até então entendidos como não econômicos, ou seja, tipos de relação que pertenciam mais à democracia, à sociologia, à psicologia e à psicologia social passam, agora, pelo crivo econômico (Foucault, 2008). 
É a partir do mercado que as políticas governamentais passam a ser avaliadas como válidas ou inválidas. Nessa racionalidade, o indivíduo aparece como um empresário de si mesmo, que administra sua vida como se fosse uma empresa. É o retorno ao que Foucault (2008) chama de Homo Oeconomicusdo neoliberalismo. Assim, a questão, tal como traz Foucault (2008), é pensar como esse indivíduo que se comporta economicamente, aplica seus recursos a fins alternativos. Estudar como se constitui e se acumula este capital humano, permite a expansão da análise econômica a áreas da vida inteiramente novos.

Para que essa generalização aconteça, o Homo Oeconomicus deve ser identificado à uma conduta racional, ou seja, aquela conduta sensível às modificações do meio e responder a elas de forma sistemática. Sendo o Homo Oeconomicus neoliberal aquele que aceita a realidade e responde às modificações do meio de maneira sistemática segundo seus interesses individuais, ele se torna um sujeito governável.

$\mathrm{Na}$ realidade brasileira, como já citado, o aumento das forças neoliberais no país marca decisivamente as ações de centralização do Estado e o direcionamento das políticas públicas, alojando essas práticas numa racionalidade biopolítica.
Dentro dessa racionalidade, todas as condutas individuais ou coletivas que prejudiquem o desenvolvimento de capital humano e o bom investimento de seus recursos devem ser objeto de problematização e intervenção estatal. É justamente na concretização das políticas públicas que aparecem as técnicas de governo que acompanham os movimentos da população de perto e que passam a regular todos os aspectos da vida de um indivíduo. Condicionando as possibilidades de ação da população.

Para Gallo (2017), o que existe no Brasil é uma governamentalidade democrática em que antes de serem passíveis de governo, os sujeitos brasileiros são primeiro constituídos como cidadãos para que sejam governados de forma democrática e não autoritária.

De forma direta ou indireta, a constituição do cidadão é alvo de todas as políticas públicas, e o único consenso da diversidade de discursos sobre a reabilitação psicossocial, tornando-se urgente a reflexão crítica de modo que não reproduzamos as relações de poder em nome dos valores universais. Desse modo, com esses direcionamentos nos questionamos: quem são considerados cidadãos no Brasil? Quais os agenciamentos que culminaram na proibição das drogas? De que modo as 
drogas, de demarcador cultural passaram a ser um problema mundial social e de saúde?

\section{Acompanhando processos: seguindo as pistas da cartografia}

Nessa jornada contamos com a ferramenta metodológica trazida por Deleuze e Guattari (1996), a cartografia. Cartografar, conforme traz os autores, é produzir um mapa aberto, desmontável, conectável em suas dimensões, reversível e suscetível a mudanças. Fazer cartografia é traçar um mapa das forças que compõe um dispositivo móvel e conflituoso, é desenrolar suas linhas e avalia-las (Deluze, 1996).

Um ponto importante sobre a pesquisa cartográfica é que ela acontece no plano da experimentação. Nesse sentido, a pesquisa se dá pela imersão em campo, que produz um agenciamento entre pesquisador e objeto, teoria e prática (Passos \& Barros, 2015).

É com os direcionamentos das pistas cartográficas que mergulho no cotidiano de um Centro de Atenção Psicossocial álcool e outras drogas de uma cidade do interior de Goiás por cerca de dois anos entre 2017 e 2018. Procurei atentamente tudo aquilo que fugia ao ordinário, que perturbava (Fonseca,
Nascimento \& Maraschin, 2015). Acompanhei a rotina de profissionais e usuários, participando das atividades, especialmente do grupo de convivência, cujos objetivos abrangem diversos aspectos importantes da reabilitação psicossocial: promoção de sociabilidade, troca de afetos, intermédio de relações, autonomia e exercício da cidadania, assim como fortalecimento do protagonismo do usuário. Utilizo também materiais produzidos pela unidade que versam sobre o tema, como panfletos informativos, folders e jornal produzido por oficina terapêutica.

Sabendo que a pesquisa pressupõe uma política de narratividade e da importância de adotar processos de escrita que deem visibilidade a construção coletiva do conhecimento, trazendo a multiplicidade das vozes implicadas no pesquisar (Barros \& Passos, 2015; Barros \& Kastrup, 2015), todos os encontros que tive durante a pesquisa foram registrados em um diário de campo. A narrativa da pesquisa por meio do diário de campo coloca pesquisador e pesquisados em um mesmo plano implicacional no qual ambos se dissolvem como entidades definitivas e preconstituídas, além de permitir a emersão dos desdobramentos de pesquisa (Barros \& Passos, 2015) 
A partir do diário de campo, mapeamos algumas linhas que atravessam o dispositivo da reabilitação psicossocial de usuários de álcool e outras drogas, aos quais mostraremos a seguir. Dado que a cada regime de verdade sobre as drogas, os problemas criados e as soluções encontradas são condizentes a essas regras. Assim, é importante fazermos alguns recortes históricos do proibicionismo e suas perspectivas de cuidado para melhor compreendermos como suas linhas de saber, poder e subjetivação que atravessam o dispositivo que estamos estudando.

Também evitamos o engodo de pensar a questão das drogas de forma binaria, na qual em uma ponta se aloja o diagrama proibicionista e de outro diagrama antiproibicionistas, mas como ruptura. Assim, passamos a mapear algumas de suas principais linhas de força, que evidenciam uma agonísticas de forças, problemáticas, como parte de uma rede de saberes/poderes que, como traz Alarcon (2008), se complementam estrategicamente de modo a perpetuar as drogas, e não eliminá-las. E, assim como coloca o autor, ao perpetuar a questão das drogas preservam-se os dispositivos de intervenções sobre elas, gerando a linha da subjetivação. Dessa forma, conforme o autor, tais dispositivos, sejam eles de interdição das drogas, sejam de tolerância, aumentam a eficácia em controlar a vida em aspectos cada vez mais íntimos.

Pela nossa perspectiva de análise na cartografia descrevemos a proveniência das forças que deram condições para a emergência de um objeto novo, como, práticas, saberes e modos de subjetivação, tendo como norte a tensão, a agonística geradas pelo diagrama do proibicionismo e do antiproibicionismo.

Diagrama do Proibicionismo: dos saberes, dos poderes e produção de processos de subjetivação que negam o consumo de drogas.

Nem sempre as drogas foram consideradas um grave problema social e de saúde. O álcool, por exemplo, entre os séculos XV e XIX, foi um referencial simbólico importante nas formações e diferenciações das identidades culturais da Europa. É no final do século XVIII, no contexto das revoluções industriais, que o consumo excessivo de álcool aparece como desvio moral e fraqueza de caráter. Nesse período, com a pressão das classes dominantes, a medicina se propõe a resolver essa questão. No final desse mesmo século, com as publicações de Thomaz Trotter, a embriaguez aparece pela primeira vez como doença, consolidando 
assim o uso de álcool objeto da medicina (Marques, 2001; Sales, 2010).

Drogas: educar para evitar. Chamava um folheto informativo sobre as drogas produzido pelo CAPS. (...) A figura desenhada na primeira página era o $D r$. Futurito, um médico. Dr. Futurito em meios de cérebros, neurônios e fórmulas químicas, dialogava com o leitor, respondendo algumas perguntas, explicando a atuação das drogas no sistema nervoso central relacionando esse mecanismo bioquímico à causa da dependência delas. (Diário de campo).

Linhas dos saberes do proibicionismo: se as drogas passaram por processo intenso de interdição e repressão foi porque se constituiu outro regime de verdade sobre elas. Na constituição dessa verdade destacamos duas linhas principais dos saberes, da medicina e a do jurídico. A aliança entre esses dois saberes proporcionou um novo saber/poder sobre as drogas, pautados em estudos científicos que evidenciavam a toxidade das drogas e a consequente degradação do corpo, assim como estudos que associavam as drogas a pobreza e a criminalidade.

Buscamos na história os agenciamentos que permitiram a emersão e fortalecimento das políticas proibicionistas, principalmente no Brasil. Como nos mostra Beauchesne (2015), no cenário internacional, a criação dos medicamentos à base de ópio, conhecido como Láudano, que encarregou à medicina do conhecimento formal sobre a substância; o advento das multinacionais farmacêuticas; e o uso do ópio pelas classes populares foram eventos importantes nesse processo.

No Brasil, a preocupação com consumo de substâncias psicoativas esteve ligada ao controle de populações específicas. Já no período colonial se observava a inquietação, principalmente da igreja, com a gestão das práticas do consumo de álcool pelos indígenas, principalmente daqueles que resistiam à colonização, porém, somente no século XIX que as drogas passaram a ser objeto da medicina, quando foram introduzidas as primeiras técnicas de anestesia com o éter e o clorofórmio. Nesse período havia também a preocupação com o uso de drogas pela população mais pobre e escravos (Adiala, 2011; Sales, 2010).

Se a medicina brasileira do século XIX foi fortemente influenciada pela medicina francesa de Esquirol e Morel, no século XX passa a ser influenciada pela medicina de Kraepelin, tornando a ação da psiquiatria mais específica e ao mesmo tempo mais abrangente. Nesse período, as discussões sobre as drogas se centravam no álcool. Em 1930 os discursos sobre as 
drogas no Brasil passam a fazer parte também dos discursos policiais, concentrando-se na proibição da maconha. A distinção entre os vícios de cocaína e morfina, considerados elegantes, com o vício da maconha, considerado vulgar produz diferenciação do tipo de repressão usada em cada caso, assim como a população reprimida (Portocarrero, 2002; Adiala, 2011).

Os discursos médicos e juristas predominaram até que emergem no âmbito nacional estudos com caráter sociológico, emergindo também as questões sociais que envolvem o uso de drogas. Na década de 70 o paradigma proibicionista já estava consolidado no país, materializando-se em dispositivos de segurança e normalização como as leis $n^{\circ} 6.368 / 76$, lei $n^{\circ} 10.490 / 02$, e lei $\mathrm{n}^{\circ} 11.343 / 06$. Ainda sob o regime de verdade médico-jurídico, é nos anos 90 que começa abertura dos discursos sobre as drogas (Adiala, 2011; Neves, 2015).

Com a abertura para discursos progressistas na década de 90 a efetividade das ações proibicionistas começou a ser colocadas em questão, possibilitando a emersão de debates sobre a descriminalização e legalização de determinadas drogas. Em 2002, articulamse diversos saberes para construção da Política de Atenção Integral ao usuário de álcool e outras drogas, do Ministério da
Saúde, alinhada aos princípios da reforma psiquiátrica e instaura a redução de danos como principal diretriz.

Em 2006, foi promulgada a lei 11.343 que institui o Sistema Nacional de Políticas Públicas sobre Drogas - Sisnad (Brasil, 2006). Para Gomes-Medeiros, Faria, Campos e Tófoli (2019) a lei, embasada na prevenção do uso indevido e reinserção social dos usuários de álcool e outras drogas, e, ao mesmo tempo na repressão à produção e tráfico de drogas ilícitas, articulou um discurso criminalizante, endereçado aos comerciantes de drogas, e um discurso médico-social que contemplaria os usuários de drogas.

Não obstante, desde 2016, nota-se um movimento crescente de contrarreforma no país no campo da saúde mental. No âmbito das políticas de drogas, em 2019 aprova-se a Lei 13.840 (Brasil, 2019) que reafirma a política proibicionista e violenta do Estado, e retorna abstinência como principal diretriz.

Linhas do poder: o racismo de Estado no proibicionismo, os hospitais psiquiátricos e as comunidades terapêuticas.

\footnotetext{
O horário se apertava, era preciso encerrar o encontro daquela semana. Com o encerramento, a pergunta: ' $E$ aí, qual $o$ tema do próximo encontro?' 'Aquele, da
} 
diferença de pele', disse um usuário passando o dedo em seu braço negro. $\mathrm{O}$ filme escolhido pra abordar o tema foi Homens de honra. (...) O filme acabou e os olhos se dispersaram, mas elevaram-se as vozes: (...)“Eu conheci num lugar desses. Pessoa estudada e comandava uma grande igreja da cidade. Nós chegamos e foi lá e chamou a gente. Fui. 'Preto aqui nem pensar, preto aqui nem bispo nem papa nem padre se for preto, aqui não’. Falou desse jeito. (...)'Preto não tem vez, aqui não'." Outro usuário até então calado se posicionou:"Eu já assisti muita partida de futebol que ficam chamando de macaco, de preto sem dinheiro... A gente tem que viver com isso neh, lidar com isso (...)”. (Diário de campo).

O Racismo teve papel fundamental na instituição do proibicionismo como regime de verdade sobre as drogas. O discurso médico-farmacêutico em aliança com o discurso racista de certos discursos religiosos contra os chineses foi fator crucial para a proibição do ópio. Da mesma forma que com os chineses, o racismo contra os negros dos guetos americanos contribuiu fortemente para a proibição da cocaína (Beauchesne, 2015).

No Brasil não foi diferente, autores como França (2016) ressaltam que, assim como nos Estados Unidos, a guerra às drogas no Brasil se configura estrategicamente como guerra contra certos grupos sociais e étnicos. Como destaca o autor, existe uma seletividade penal no país, no qual os indivíduos encarcerados pela legislação vigente sobre drogas são, preponderantemente, aqueles pertencentes às populações não brancas e pobres. Ainda conforme França (2016), o racismo como estratégia estatal para controle de determinados grupos sociais se mostra como produção de uma identidade deteriorada daqueles que fazem uso de alguma substancia psicoativa.

Foucault (2002) no curso “ Em defesa da sociedade" demonstra que o discurso racista foi um episódio do grande discurso de guerra das raças, que foi retomada no final do século XIX em termos sócio-biológicos com finalidades essencialmente de conservadorismo social e, em certos casos, colonização. Nas sociedades baseadas na biopolítica, cujo poder visa o prolongamento da vida, o racismo tem a função essencial de fazer um corte entre o que deve viver e o que deve morrer. Ao fragmentar o contínuo biológico em raças, o racismo cria uma hierarquia entre as raças, com a incumbência de defasar no interior da população uns grupos em relação a outros.

Nesse sentido, entende-se que a biopolítica já possui em sua origem elementos assassinos, pois somente uma parte da população, muitas vezes branca europeia e norte americana que tem 
determinadas condições socioeconômicas e étnicas possuem efetivamente direito de viver, tendo acesso à segurança, educação, saúde, seguridades sociais pois podem pagar por esses "serviços".

A moldura neoliberal da biopolítica determina as regiões que terão acesso as políticas públicas mencionadas acima e exclui, ou deixa morrer, ou literalmente mata a população moradoras das periferias das cidades e dos países da África, América Central e do Sul, Oriente Médio e determinados países asiáticos, etc, que por sua vez foram colônias um dia. Essas políticas de extermínio de uma determinada parte da população são muitas vezes justificadas pelos governantes por teorias médicas e criminológicas eugênicas do século XVIII e XIX.

Nesse sentido, entendemos que o discurso neoliberal justifica uma política de morte ao desproteger, desqualificar, incriminar ou reificar uma determinada parte da população. Por exemplo, um ex usuário de álcool e drogas nunca deixará de sê-lo por mais adaptado que esteja, esse é seu lugar.

Conforme Foucault (2002) é permitir uma relação "positiva" com a vida ao matar, isto é, quanto mais deixar morrer, mais viverá. $\mathrm{O}$ racismo estabelece uma função de seleção biológica na biopolítica determinando na população quem vive e quem é deixado morrer, ou melhor faz morrer a raça inferior, deixando assim a espécie mais saudável e pura. O racismo é o elemento da biopolítica que assegura o direito de matar do Estado.

É priorizando a segurança da espécie e assegurando sua qualidade que os dispositivos de tratamento de drogas sob essa perspectiva são organizados, ao mesmo tempo em que utilizam de técnicas de poder disciplinares centradas no corpo individual, em sua separação, alinhamento, vigilância, objetivando o aumento da força útil desse corpo por meio do treinamento, da racionalização e economia de um poder que deve se exercer através de um sistema de vigilância e hierarquia. (Foucault, 2002a).

A problemática principal dessa discussão é pensar qual é a função do racismo na moldura neoliberal da biopolítica atual brasileira, como é o caso do Brasil que vivencia o retorno e fortalecimento de políticas proibicionistas, moralistas e punitivas, que promovem o genocídio da população negra e indígena no país e a intensificação das desigualdades sociais. Como bem apontam Alvarenga, Silveira e Teixeira (2018), o crescente discurso conservador e preconceituoso sobre as drogas e seus usuários, a violência contra essa população recebe autorização, assim como as práticas 
anteriores à Reforma Psiquiátrica capitaneada pelos interesses das grandes corporações privadas de saúde e pelas comunidades terapêuticas.

Os hospitais psiquiátricos e as comunidades terapêuticas hoje se configuram como dispositivos relevantes na atenção ao álcool e outras drogas. O hospital, local privilegiado para o exercício do poder médico, sob as justificativas de, em primeiro lugar, garantir sua segurança pessoal e da família, libertá-los da influência do exterior, vencer resistências pessoais, submetê-los ao regime médico e impor novos hábitos intelectuais e morais (Foucault, 2006).

Além, como é o caso da realidade brasileira, do racismo determinar nas práticas manicomiais quem fica internado nos hospitais psiquiátricos e nas clínicas de reabilitação, ou encarcerados nos manicômios judiciários, pois há nestas práticas a ideia que o negro e o indígena são mais perigosos já que são entendidos como "quase animais” (Diário de campo).

As comunidades terapêuticas, análogas aos manicômios, são serviços de internação na modalidade de moradia para usuários de drogas. Elas representam o ponto de encontro entre as instituições de justiça, instituições de saúde e a moral religiosa, uma vez que essas comunidades são o destino privilegiado daqueles que possuem a doença crônica e incurável da dependência química, cuja justiça determina internação compulsória. $\mathrm{O}$ tratamento busca a mudança do comportamento dos indivíduos através da criação de valores geralmente de bases religiosas(Fossi\& Guareschi, 2015).

\section{Diagrama do Antiproibicionismo}

Como se deu o agenciamento da reabilitação psicossocial com as drogas? Conforme supracitado, no Brasil, a questão das drogas era prioritariamente delegada aos dispositivos médicos-jurídicos. Porém, com os movimentos da Reforma Psiquiátrica e a abertura dos debates sobre a efetividade da interdição sobre as drogas, começa-se a pensar novas formas de lidar com a questão, assim como a exigência de uma política pública específica sobre o tema.

A Política Integral de Álcool e Outras Drogas do Ministério da saúde de 2003, além de fazer a passagem para o campo da saúde coletiva, alinha a política oficial sobre drogas aos preceitos da reforma psiquiátrica e agenciando as drogas com a reabilitação psicossocial. Essa política também marca a instituição da redução de danos como política oficial, a qual é direcionada por princípios antiproibicionistas. Como se deu a abertura 
dos debates sobre as drogas na produção de um novo regime de verdade?

O dia estava quente. Enquanto enchia a garrafa de água, dois técnicos da equipe e um policial conversavam próximo. $\mathrm{O}$ assunto chamou-me atenção, falavam sobre legalização das drogas. O policial e um dos técnicos se posicionavam veemente contra, alegando que a facilidade de acesso aumentaria o uso de drogas, e consequentemente o número de "viciados". A mulher mexia em seu café, pensativa, por fim, disse: 'Ah, sabe que еи não sei. Ainda estou formando minha opinião, mas estou tendendo a ser a favor viu? Andei vendo uns vídeos, e depois que assisti a uma audiência pública sobre a maconha, comecei a mudar de opinião' (Diário de campo).

Linha dos saberes do
antiproibicionismo: é no pós-segunda guerra mundial, com a ascensão dos debates em torno dos Direitos Humanos, que se forma o cenário adequado para o questionamento da efetividade das políticas proibicionistas e das soluções encontradas para o problema das drogas. Inicia-se um movimento de indagação do próprio saber científico que embasa tais políticas. Todos os questionamentos vão permitindo uma abertura nos debates sobre as drogas e a produção de uma nova verdade sobre elas.
Para a Beauchesne (2015), as pesquisas que embasaram a interdição das drogas baseadas em sua toxidade se apoia me metodologias fracas e preconceitos morais. A autora nos mostra que duas grandes pesquisas tiveram papel fundamental no questionamento no saber científico das drogas e consequentemente a abertura das políticas: a pesquisa de Robins com soldados americanos que lutaram no Vietnã e a pesquisa de Bruce Alexander publicada em 1981, conhecida como Rat Park.

Ambos os estudos contrariaram os resultados de pesquisas que apontavam que as drogas tornavam o indivíduo automaticamente dependente e que a dependência das drogas era irreversível. Ainda demonstraram que fatores como contexto que o indivíduo está inserido e qualidade da substancia, são elementos importantes quando se fala em adicçãoem drogas (Beauchesne, 2015).

Com o aparecimento de um novo regime de verdade sobre as drogas agora direcionadas pelo discurso da saúde pública, as drogas não mais configuram como o grande inimigo público, mas parte da história e sobrevivência do ser humano começa-se a se pensar novas possibilidades de cuidado para seus usuários.

Linha do poder redução de danos: 
Um livreto em amarelo fluorescente em pé em no Balcão que separava o espaço da mesa com as cadeiras da recepção, com os dizeres: REDUÇÃO DE DANOS respeita a liberdade de escolha, não exigindo abstinência. Saúde e cidadania. (...) Até então nunca havia observado nenhum material que fizesse alusão à redução de danos, embora o tema fosse constantemente abordado entre a equipe. Fiquei me perguntando se a introdução desse livreto no ambiente tivesse relação com a tensão entre a equipe, que estava em processo de crescimento com a modulação do serviço para CAPS ad III. Parte dos profissionais defendiam posturas mais tolerantes e pedagógicas em relação ao usuário que chegava sob efeitos de drogas ou faziam uso dentro da unidade, e parte defendia posturas mais rígidas baseadas no sistema de punição e disciplina. (Diário de campo).

Com as novas urgências emergidas no campo de álcool e outras drogas há um grande investimento na política que teve início com o relatório de Rolleston, e implementada na Inglaterra em 1926, isto é, na política de redução de danos. Diversos países europeus, como Holanda, França e Portugal começaram a repensar as formas de lidar com seus usuários de drogas a partir dessa nova perspectiva.

No Brasil, as práticas de redução de danos se iniciaram no momento das epidemias das doenças sexualmente transmissíveis como uma possível solução para os crescentes casos de HIV, sendo Santos a cidade pioneira. Com resultados satisfatórios dessa experiência, as práticas de redução de danos foram se expandindo pelo território nacional até que passa a direcionar oficialmente as políticas públicas sobre drogas.

Nas políticas sobre drogas, a redução de danos passa a ser considerada como uma política divergente da política de combate às drogas, uma prática de saúde pública que se respalda no discurso dos direitos humanos, defesa e ampliação da vida, sendo uma postura ético-política sustentada na ideia de diminuir o efeito deletério do uso de drogas (Siqueira, 2014).

Desde 2016, nota-se mudanças nas políticas de saúde mental direcionadas por movimentos conservadores contra a Reforma Psiquiátrica, que também impactaram as políticas de drogas do país. Em 2019 foi aprovada outra política de drogas, que muda de forma significativa o cuidado de usuários de álcool e outras drogas no país. A política aprovada nesse ano retoma a abstinência como principal diretriz e enfatiza o cuidado desses usuários em dispositivos como comunidades terapêuticas e hospitais psiquiátricos. Com a política recentemente aprovada, a questão das drogas volta a ser 
prioritariamente delegadas aos dispositivos médicos-morais.

Com os retrocessos das políticas públicas em saúde mental notados desde 2016, especialmente no campo de álcool e outras drogas, nos questionamos como se posicionar a favor da vida nas práticas de reabilitação psicossocial (redução de danos) sem cair nos próprios processos de normalização e de empreendedorismo neoliberal que permitiram sua emergência?

\section{Linhas de força e composições da} Reabilitação psicossocial de usuários de álcool e outras drogas no Brasil

No que diz respeito à reabilitação psicossocial, no Brasil, há uma heterogeneidade discursiva, de modo que esse campo pode ser pensado a partir de um vasto acervo teórico e pouco coeso. Apesar de ganhar destaque com o movimento da Reforma Psiquiátrica, as práticas de reabilitação psicossocial perpassam tanto pelos discursos proibicionistas quanto antiproibicionistas e apesar das diversas tendências discursivas encontram no exercício da cidadania seu ponto de convergência, todas considerando a reabilitação psicossocial uma postura ética. (Bayer et al., 2011; Guerra, 2004; Pitta, 2016). A partir do diário de campo faço a tessitura do diagrama da
Reabilitação psicossocial, apresentando suas linhas a seguir, articulando com os diagramas do proibicionismo e antiproibicionismo.

Linha um- As oficinas de geração de renda e economia solidária: fortes influências de autores da reforma psiquiátrica italiana, são consideradas na literatura nacional importantes ferramentas de reabilitação psicossocial. Conforme Rotelli (1994) a reabilitação psicossocial pode ser pensada pela reinserção dos pacientes no mercado de trabalho e no empenho na construção de cooperativas de trabalho.

\footnotetext{
Existem variados projetos e ações que objetivam a reabilitação psicossocial dos usuários que participam do CAPS ad, e cada um desses projetos se embasa em uma concepção diferente do que seja reabilitação psicossocial. A oficina de artesanato é considerada ao mesmo tempo uma oficina de geração de renda e oficina de terapia ocupacional. (Diário de campo).
}

Dependendo das linhas evidenciadas no dispositivo, a reabilitação psicossocial dos usuários de álcool e outras drogas pelo trabalho podem ser pensadas de diferentes maneiras. Quando as linhas do proibicionismo se destacam e direcionam o dispositivo, tais oficinas podem ser pensadas como o trabalho como uma prática curativa (Santos \& Yassui, 
2016), e de entretenimento (Saraceno, 2001), concretizadas nas clássicas oficinas de terapia ocupacional.

A depender da linha, a reinserção não só no mercado de trabalho, mas na própria comunidade, se dá apenas após o período de desintoxicação da droga usada, ou seja, apenas após um período de abstinência. É o que defende autores como Bonadio (2010). A autora considera que dado o caráter crônico da doença da dependência química, existe uma necessidade de suporte em longo prazo para que esses doentes reestabeleçam os setores cotidianos prejudicados na vida, como o trabalho e relações sociais, sendo a abstinência a possibilidade do primeiro passo para a reabilitação psicossocial.

Já Duailibi e Ribeiro (2010) são bem mais enfáticos nesse quesito. Para os autores, a reabilitação psicossocial só se inicia necessariamente após a abstinência da substancia. Tal reabilitação deve visar à construção de um novo estilo de vida que seja incompatível com o consumo de drogas e mais adaptável ao objetivo da abstinência.

No entanto, quando se direcionadas pelo regime de verdade do antiproibicionismo, o uso da substancia sai de foco, e passa-se a se pensar no trabalho como um aspecto do projeto de vida do indivíduo, no qual ele é o meio de sustento e realização pessoal (Saraceno, 2001). Assim, as cooperativas e economia solidárias passam a ser principais ações. Cabe ressaltar que a tensão gerada pelos diagramas proibicionistas e antiproibicionistas evidenciadas pela oficina de artesanato do CAPS ad, coexistem e se tencionam constantemente no dispositivo.

O grupo de convivência, dentro da perspectiva da clínica ampliada, propunha a promoção de sociabilidade, troca de afetos, autoestima, autonomia e exercício de cidadania. Além do fortalecimento do protagonismo dos usuários por meio de atividades que fomentem a participação destes nos processos de gestão do grupo. (...) As oficinas de jogos eram recentes, começaram a ser feitas quando aumentaram os números de profissionais. Para alguns desses profissionais era uma forma de manter os usuários em acolhimento diurno ocupados, evitando brigas e desentendimentos. Para outros, era ótima oportunidade de reabilitação psicossocial, uma vez que poderiam ser trabalhados afetos, regras e frustrações. (Diário de campo).

Linha dois - Clínica Ampliada: a associação da reabilitação psicossocial com a noção de clínica ampliada, como instrumento reabilitativo também é encontrada na bibliografia acerca do tema, e parte do pressuposto que em determinado momento e situação pode existir uma 
psicodinâmica e uma escolha (Brasil, 2004).

No campo das adicções, a clínica ampliada é intimamente ligada à redução de danos. Assim, a redução de danos como uma forma de clínica ampliada, considera que a escolha de continuar o uso ou não cabe ao indivíduo, por isso não se trata de buscar a abstinência. Assim, estar fazendo uso ou não da substancia não é a questão primária, mas a manutenção de uma vida produtiva, com afetos regulados, e desejos modulados.

Linha três - Recovery andempowerment (reestabelecimento e empoderamento): Evidenciada após a IV Conferência de saúde mental (Conselho Nacional de Saúde [CNS] 2010), quando se pontuou a necessidade de reavaliação das práticas de reabilitação psicossocial nos serviços da rede de atenção psicossocial, essa linha é orientada em grande parte pelas políticas americanas de saude mental. Com a noção de reestabelecimento e empoderamento a responsabilidade pelo processo reabilitativo é do indivíduo.

Calcado na individualidade do indivíduo, algo tão valorizado para o governo neoliberal, e visando a promoção do processo de reabilitação criam-se ferramentas como o Plano de Ação para o Bem-estar e recovery, no qual se configura como uma ação educativa e reflexiva para autoconhecimento, objetivando a gestão das próprias vidas, diminuindo a dependência dos serviços de saúde. Criamse habilidades emocionais e físicas suficientes para que os corpos, antes inúteis, tornem-se produtivos.

\section{Linha quatro- Jornal do CAPS: O} fragmento abaixo traz outro projeto de reabilitação psicossocial promovido pelo CAPS ad que foi o campo de experimentação da pesquisa, a produção de um jornal. Dessa vez, o projeto visa um aspecto da reabilitação psicossocial para além do indivíduo, a comunidade. O jornal, com influencias da Reforma Francesa, propõe criar uma forma de comunicação entre comunidade e usuários, e levar para população outro olhar sobre estes, para melhor incluí-los.

O jornal contava com duas edições, e a terceira estava no forno. Na primeira edição já se justificava: $O$ projeto do jornal "Voz do CAPS ad" surgiu das discussões do grupo de convivência, que acontece todas as quartas-feiras à tarde no CAPS ad Viver. A construção do jornal envolveu equipe e usuários que reivindicavam formas de serem ouvidos pela comunidade. (...) Assim, nos engajamos nesse projeto para possibilitar livre expressão destes usuários, para que possam compartilhar o dia-a-dia de suas realidades objetivas e subjetivas. O jornal configura-se como uma poderosa 
ferramenta de interação social $e \quad o$ primeiro passo em direção ao exercício da cidadania, objetivos tão caros ao CAPS. (Jornal Voz do CAPS ad- Diário de Campo).

Se 0 processo de desinstitucionalização ou desospitalização, eixo central da maioria das Reformas Psiquiátricas, abriu as portas dos hospitais psiquiátricos, era preciso criar estratégias para preparar as comunidades para receber esse contingente de pessoas que antes estavam asiladas (Anthony \& Farkas, 2009; Desviat, 1999 como citado em Guerra, 2004).

Esse aspecto da reabilitação psicossocial de usuários de álcool e outras drogas são um dos poucos consensos entre os estudiosos do assunto. Os poucos autores que se dedicam ao tema frisam a importância da reeducação social, no sentido de diminuir o estigma e a exclusão social dos usuários de substâncias psicoativas. Isto é, de levar para o público os novos regimes de verdade sobre as drogas, ou perpetuar e fortalecer os regimes já constituídos, dependendo da direção proibicionista ou antiproibicionista que a constituição do dispositivo toma.

Nesse ponto a tensão entre os diagramas proibicionistas e antiproibicionistas se manifesta de forma clara. Tendo como uma das consequências a perpetuação da noção das adicções enquanto dependência química, ou seja, uma doença crônica. Apesar das ações desse tipo serem pautadas nas diretrizes da reforma psiquiátrica, como inclusão social e exercício da cidadania, e na popularização das estratégias de redução de danos, muitas vezes o processo de inclusão se dá dessa forma, a inclusão é feita pelo papel de doente que o indivíduo fará, e é esse lugar que ocupará socialmente.

É na figura do dependente químico que, para Alarcon (2008), sustenta a tensão entre a interdição e a tolerância, estando entre as duas linhas que orientam abordagens e tratamentos possíveis e aprovados pelo Estado brasileiro. É ao redor de sua figura que se organizam os discursos sobre o valor das drogas de forma geral. A existência desse personagem, considerado doente mental, incapaz e criminoso, parece ser sempre motivo para toda uma série de medidas preventivas de gestão de riscos e redução de danos (Alarcon, 2008).

Linha de resistência: caminhamos até aqui no rastro das linhas de poder/saber do dispositivo, nas linhas de subjetivação que modulam os aspectos mais íntimos da vida de um sujeito, como o uso de drogas. No entanto, há também nos dispositivos as linhas de resistências. Existe nos 
dispositivos uma dimensão de singularização, que resiste às linhas de poder e se inventa. Quais seriam elas na reabilitação psicossocial de usuários de álcool e outras drogas?

Pinho (2009) nos deixa valiosa pista em sua tese sobre o mesmo assunto. No entendimento da autora, a reabilitação psicossocial de usuários de drogas não consiste em desenvolver habilidades perdidas por meio das atividades desenvolvidas nas oficinas. Para além do desenvolvimento de habilidades úteis para o mercado de trabalho, ela deve ter um vista a produção de autonomia, negando qualquer tutela.

Assim, a autora elenca a redução de danos como uma estratégia valiosa no processo reabilitativo visto que respeita o direito de escolha dos indivíduos, bem como suas singularidades. Eis aqui a nossa aposta: a reabilitação psicossocial de usuários de álcool e outras drogas agenciada à Redução de Danos.

O que era a liberdade para o Hippie, que há três meses frequentava diariamente o CAPS? Ele deixou bem claro: "Cara, liberdade é a liberdade. Hippie mesmo não aguenta ficar parado numa cidade. (...) A gente não consegue ficar preso a um sistema. Não que eu esteja trabalhando, mas é um sistema você sair oito horas da manhã nem que seja pra ir pra praça abrir um painel de artesanato, você acaba dentro do sistema. Então a liberdade pra mim é isso, é você olhar aquelas linhas da estrada, olha a estrada sem final assim, só vai... para numa praia, fica dois três dias $e$ já vaza. Você falar de liberdade $e$ continuar morando em uma cidade grande pra mim é meio hipocrisia. Não é liberdade”. (Diário de campo).

Nos últimos anos do trabalho de Foucault começa aparecer o elemento da resistência na conduta humana: o $\quad s i$ mesmo. O si mesmo é um conceito que indica uma ação própria do indivíduo. Foucault (1985) mostra que nos primeiros séculos destacam-se nos textos filosóficos e médicos a insistência acerca da atenção a ter consigo mesmo. Essa preocupação, conforme Foucault (1985) não se concretizou em códigos que proíbem determinados atos, mas sim em uma intensificação da relação consigo mesmo na qual o indivíduo é o sujeito de seus atos.

Em $O$ sujeito e o Poder, Foucault (1995) afirma que uma série de resistências apareceu nos últimos anos, dentre as quais se encontram as resistências contra a administração sobre os modos de vida. Ao retornar às éticas greco-romanas antigas, Foucault trata a questão da liberdade. Não mais a liberdade neoliberal, mas a liberdade como a ética do cuidado de si. Trata-se de uma liberdade da ordem da experiência, da invenção, na qual os indivíduos inventam seu modo de existir, 
em que o sujeito é objeto da própria verdade construída de forma processual (Sousa, 2007).

Marthin Luther king, Nelson Mandela, Jesus Cristo... Cara, o cara era louco, corria contra a maré. Acho que a gente tem que pegar essa loucura que a gente tem de tentar ser honesto, de tentar correr pelo certo no mundo errado". (Diário de Campo).

Foucault, em entrevista, expressa sua frustração que os temas das drogas sejam sempre tratados em termos de liberdade e proibição. Para ele, as drogas devem ser elementos culturais, inclusive enquanto fonte de prazer e devem ser estudadas, experimentadas e fabricadas boas drogas. "Da mesma forma que há boa música e má música, há boas e más drogas. E, então, da mesma forma que não podemos dizer somos "contra" a música, não podemos dizer que somos "contra" as drogas" (Foucault, 2004, p. 265).

Ao apostarmos na Reabilitação Psicossocial de usuários de álcool e outras drogas associada a uma postura política de redução de danos, apostamos nas potencialidades dessas práticas na construção de uma ética da existência do sujeito, a partir de suas experiências, sem colocar interdições às suas experiências prazerosas. Um dispositivo de linhas flexíveis como a redução de danos permite um processo de individuação que escapa às linhas de força e aos saberes já constituídos, resultando na criação de maneiras originais de existir no mundo.

\section{Considerações Finais}

Embora sempre presente na história da humanidade, as drogas foram capturadas pelos discursos médicos e jurídicos resultando em interdições no consumo dessas substâncias, controle e genocídio de determinados grupos sociais. Com a emersão dos direitos humanos como uma variável relevante na avaliação das políticas, as práticas proibicionistas são questionadas possibilitando abertura desses discursos para políticas mais progressistas.

No Brasil, é justamente no contexto da Reforma Psiquiátrica no país que as práticas de reabilitação psicossocial se agenciam às drogas, criando práticas reabilitativas voltadas à essa população. Apesar disso, os regimes de verdade proibicionista, pautadas nos saberes psiquiátricos-jurídicos coexistem e também compõem esse dispositivo e nos últimos anos voltam a compor as diretrizes das políticas públicas nesse âmbito.

Dentro do discurso neoliberal, as práticas de reabilitação psicossocial assumem o modelo de empreendedorismo econômico, intervindo diretamente nos 
indivíduos para produção de habilidades necessárias, assim como inteligência emocional para o mercado, modulando também, por meio da apropriação das práticas de consumo de drogas, a modulação de condutas e dos modos de sentir prazer.

No entanto, o dispositivo também permite linhas de resistência, linhas criadoras que escapam ao poder se considerarmos a reabilitação psicossocial uma estratégia para que o indivíduo dominado pelos prazeres da droga reconstitua o governo de si mesmo, passando a dominar seus prazeres, reconstrua suas relações e modos de existir, que essa reconstrução seja perpassada pelo cuidado de si como uma prática de liberdade, e não sendo inserido dentro de um código moral recheado de privações.

\section{Referências}

Adiala, J. C. (2011). Drogas, medicina e civilização na primeira república. Tese (Doutorado em História das Ciências e da Saúde) - Casa de Oswaldo Cruz / Fiocruz, Rio de Janeiro.

Alarcon, S. (2008). O diagrama das drogas: Cartografia das drogas como dispositivo de poder na sociedade brasileira contemporânea (Tese de Doutorado). Escola Nacional de Saúde Pública Sérgio Arouca/Fundação Oswaldo Cruz, Rio de Janeiro, Rio de Janeiro, Brasil. Recuperado de https://www.arca.fiocruz.br/handle/icic t/2597.

Alvarenga, R., Silveira, J.I., Teixeira, D. S. G. (2018). Política de drogas no Brasil no cenário de violações aos direitos humanos. Argum., Vitória, 10(3), p. 123-136. ago./dez. Recuperado de http://arquivos.integrawebsites.com.br/ 21979/337d691f1a6be3089756ce1deb 925ca3.pdf

Anthony, W. A., \&Farkas, M. D. (2009).Primer on the psychiatric rehabilitation process. Boston: Boston University Center for PsychiatricRehabilitation.

Barros, L. P de \&Kastrup, V. Cartografar é acompanhar processos. (2015). In Passos, E; Kastrup, V.\&Escóssia, L (Orgs.). Pistas do método cartográfico. Porto Alegre: Sulina.

Barros, R. B. \& Passos, E. Diário de bordo de uma viagem-intervenção. (2015). In Passos, E; Kastrup, V. \&Escóssia, L (Orgs.). Pistas do método cartográfico. Porto Alegre: Sulina.

Bayer, M. T., Moura, D. N., Ferreira, A. A. L. (2011, novembro). A gestão das condutas na reforma psiquiátrica: a reabilitação psicossocial como dispositivo do vir-a-sercidadão. Trabalho apresentado em GT no evento $16^{\circ}$ Encontro Nacional ABRAPSO, organizado pela ABRAPSO, Recife, Pernambuco, Brasil.

Beauchesne, L. (2015) Legalizar as drogas para melhor prevenir os abusos. Rio de Janeiro, Brasil: Editora UFRJ.

Benevides, P. S; Prestes, T. K. A. (2014). Biopolítica e governamentalidade: uma análise da Política Nacional sobre Drogas. ECOS, 4(2). p. 274-287. Recuperado de http://www.periodicoshumanas.uff.br/e cos/article/view/1333/1049 
Bonadio, A. N. (2010) Reabilitação Psicossocial de dependentes químicos: estudo qualitativo em uma residência terapêutica. Tese de Doutorado. Universidade Federal de São Paulo. Escola Paulista de Medicina. Programa de Pós-graduação em Psiquiatria. São Paulo, SP.

Brasil. (2004). Ministério da Saúde. Secretaria de Atenção à Saúde. Departamento de Ações Programáticas Estratégicas. Saúde Mental no SUS: os centros de atenção psicossocial. Brasília: Ministério da Saúde.

Brasil. Ministério da saúde. (2003) Secretaria Executiva. Coordenação Nacional de DST/AIDS. A Política do Ministério da saúde para atenção integral a usuários de álcool e outras drogas. Brasília: Ministério da saúde. Recuperado de http://www.saude.gov.br/images/pdf/2 015/marco/10/A-Pol--tica-do-Minist-rio-da-Sa--de-para-Aten----o-Integralao-Usu--rio-de---lcool-e-OutrasDrogas--2003-.pdf

Cassoli, T. (2012). Riso e estratégias de poder: alianças atuais no governo das condutas. Tese de Doutorado. Curso de pós graduação em Psicologia. Universidade Estadual Paulista, Assis, SP.

Chrispino, A. (2016). Introdução ao estudo das políticas públicas: uma visão interdisciplinar e contextualizada. Rio de Janeiro: FGV editora

Conselho nacional de saúde. (2010). Comissão Organizadora da IV Conferência Nacional de Saúde Mental Intersetorial. Relatório Final da IV Conferência Nacional de Saúde Mental - Intersetorial, 27 de junho a 1 de julho de 2010. Brasília:Conselho Nacional de Saúde/Ministério da Saúde

Deleuze, G. (1996). O que é um dispositivo. In G. Deleuze. $O$ mistério de Ariana. Lisboa/Portugal: Editora Vega.
Deleuze, G. Guattari, F. (1996). Mil Platôs (2a Ed, v.1) São Paulo: Editora34.

Duailibi, L. \& Ribeiro, M. (2010). Reabilitação psicossocial e gerenciamento de caso. In: Ribeiro, M. \& Laranjeira, R. (orgs). (2010). O tratamento do usuário de crack. São Paulo: Casa Leitura Médica.

Fonseca, T.M.G., Nascimento, M.L., Maraschin, C. (orgs). (2015). Pesquisar na diferença: um abecedário. Porto Alegre, Brasil: Sulina.

Fossi, L. B., \& Guareschi, N. M. F. (2015). O modelo de tratamento das comunidades terapêuticas: práticas confessionais na conformação dos sujeitos. Estudos e Pesquisas em Psicologia, 15(1), 94-115. Recuperado de

http://pepsic.bvsalud.org/pdf/epp/v15n 1/v15n1a07.pdf

Foucault, M. (1985). História da sexualidade III: o cuidado de si. Rio de Janeiro: Edições Graal

Foucault, M. O sujeito e o poder. (1995). In Dreyfus; Rabinow. Michel Foucault, uma trajetória filosófica: para além do estruturalismo e da hermenêutica. Rio de Janeiro: Forense Universitária.

Foucault, M. (2002). Em defesa da sociedade. São Paulo: Martins Fontes.

Foucault, M. (2004). Michel Foucault, uma entrevista: sexo, poder e a política da identidade. Verve, 5: 260-277.

Foucault, M. (2006). O poder psiquiátrico. São Paulo: Martins Fontes.

Foucault, M. (2008). O nascimento da bipolítica: curso dado no Collège de France (1978-1979). São Paulo: Martins Fontes.

França, R. (2016). Liberalismo, biopoder e racismo na guerra às drogas: notas em 
torno de uma política. Olhares Plurais, 1(14), 134-152. Recuperado de https://revista.seune.edu.br/index.php/o p/article/view/177/180

Gallo, S. (2017). Biopolítica e subjetividade: resistência? Educar em Revista, 33(66), p. 77-94. Recuperado de https://revistas.ufpr.br/educar/article /view/53865. DOI: 10.1590/01044060.53865

Gomes-Medeiros, Débora, Faria, Pedro Henrique de, Campos, Gastão Wagner de Sousa, \&Tófoli, Luís Fernando. (2019). Política de drogas e saúde coletiva: diálogos necessários. Cadernos de Saúde Pública, 35 (7), p. 1-14. Recuperado de:

https://www.scielo.br/scielo.php?script =sci_arttext\&pid=S0102-

$\underline{311 X 2019000903001 \& \ln \mathrm{g}=\mathrm{es} \& \mathrm{nrm}=\mathrm{i}}$ so\&tlng=es .dói:

https://dx.doi.org/10.1590/0102-

$\underline{311 \times 00242618}$

Guerra, A. M. C. (2004). Reabilitação psicossocial no campo da reforma psiquiátrica: uma reflexão sobre o controverso conceito e seus possíveis paradigmas. Revista Latinoamericana de Psicopatologia Fundamental, 7(2), 83-96. Recuperado de https://www.scielo.br/scielo.php?script =sci_arttext\&pid=S141547142004000200083.

Lei 11.343, de 23 de agosto de 2006, Institui o Sistema Nacional de Políticas Públicas sobre Drogas - Sisnad; prescreve medidas para prevenção do uso indevido, atenção e reinserção social de usuários e dependentes de drogas; estabelece normas para repressão à produção não autorizada $\mathrm{e}$ ao tráfico ilícito de drogas; define crimes e dá outras providências. Brasil. (2006). Recuperado de http://www.planalto.gov.br/ccivil_03/ ato2004-2006/2006/lei/111343.htm

Neves, A. S. (2015). Genealogia das políticas proibicionistas sobre drogas no Brasil, 1970-1990. Dissertação (Mestrado)- Universidade Federal de Santa Maria, Centro de ciências sociais e humanas, Programa de pósgraduação em ciências sociais, Rio Grande do Sul

Passos, E. \& Barros, R.B. (2015). Por uma política da narratividade. In: Passos, E; Kastrup, V. \&Escóssia, L (Orgs.). Pistas do método cartográfico. Porto Alegre: Sulina.

Pinho, P. H. (2009). Os desafios na atenção aos usuários de álcool e outras drogas e reabilitação psicossocial. (Dissertação de Mestrado). Escola de Enfermagem da Universidade de São Paulo. São Paulo, São Paulo, Brasil. Recuperado de https://www.teses.usp.br/teses/disponi veis/7/7134/tde-22062009123744/publico/Paula_Pinho.pdf

Pitta, A. M. F. (2016). O que é reabilitação psicossocial no Brasil, hoje? In: Pitta, A M. F. (org). Reabilitação Psicossocial no Brasil (pp. 27-36) São Paulo, Brasil: Hucitec.

Portocarrero, V. (2002). Arquivos da loucura: Juliano Moreira $e$ a descontinuidade histórica da psiquiatria. Rio de Janeiro: FIOCRUZ.

Rotelli, F. (1994). Superando o manicômio: o circuito psiquiátrico de Trieste. In Psiquiatria social e reforma psiquiátrica. Rio de Janeiro: Fiocruz.

Sales, E. (2010). Aspectos da história do álcool e do alcoolismo no século XIX. Em Escritos sobre a saúde, doenças e sociedade. UFPE. Cadernos de História, 1(7), p. 167-203. Recuperado de

https://periodicos.ufpe.br/revistas/cade rnosdehistoriaufpe/article/view/110065 $\underline{121988}$

Santos, C. E. dos; Yassui, S. (2016). Muito além do CAPS AD: o cuidado no território e na vida. In: Souza, A.C de $\&$ cols. (orgs). Entre pedras e fissuras: 
a construção da atenção psicossocial de usuários de drogas no Brasil. São Paulo: Hucitec editora.

Saraceno B. (2001). Libertando identidades: $\quad d a$ reabilitação psicossocial à cidadania possível. ( $2^{\mathrm{a}}$ ed) Rio de Janeiro: Te Corá/Instituto Franco Basaglia.

Siqueira, D. (2014). Redução de danos como ampliação da vida. In: Lancetti, A. Clínica peripatética (pp. 53-76). (9 ed). São Paulo, Brasil: Hucitec

Sousa, A., Fo. (2007). Foucault: o cuidado de si e a liberdade, ou a liberdade é uma agonística. Trabalho apresentado no IV Colóquio Internacional Michel Foucault, organizado por Universidade Federal do Rio Grande do Norte, Natal, Rio Grande do Norte, Brasil.

Sousa, A., F $F^{o}$ (2007). Trabalho apresentado no IV Colóquio Internacional Michel Foucault. Abril de 2007, Natal.

Jessica Batista Araújo é graduada em Psicologia pela UFMT e mestre em Psicologia pela UFG. Fez formação em Álcool e outras drogas pela faculdade de Enfermagem da UFG em 2019. Atua como psicóloga no Centro de Atenção Psicossocial álcool e outras drogas desde 2016, sendo também docente do curso de Psicologia da UniEvangélica.

E-mail: jeh.b.araujo@gmail.com

ORCID: http://orcid.org/0000-0003-1084$\underline{8905}$

Tiago Cassoli é professor Adjunto II da Universidade Federal de Goiás - UFG do curso de Psicologia/Regional Jataí e do Programa de Pós-Graduação em Psicologia -UFG/Regional Goiânia. Realizou doutorado em Psicologia na área: Psicologia e Sociedade pela Universidade Estadual Paulista - UNESP/ASSIS (2012) e graduação em Psicologia pela UNESP/ASSIS (2002). Possui mestrado em Psicologia: Estudos da Subjetividade pela Universidade Federal Fluminense - UFF (2006). Fez um pósdoutoramento como pesquisador visitante no Departamento de Direito Público e Filosofia Jurídica da Faculdade de Direito da
Universidad Autonoma de Madri - UAM (2020), Espanha.

Email: cassolitiago2@gmail.com

ORCID: https://orcid.org/0000-0002-9751$\underline{124 \mathrm{X}}$

Enviado em: 07/03/19- Aceito em: 02/09/20 